\title{
Diretrizes para inserção de requisitos de eficiência energética no processo de projeto de aeroportos
}

\author{
Guidelines for inclusion of energy efficiency requirements \\ in the design process of airports
}

\section{Fernanda Selistre da Silva Scheidt Ercília Hitomi Hirota}

\section{Resumo

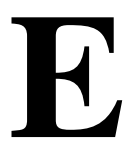

ste artigo aborda a gestão de informação na etapa de projeto visando à consideração de requisitos de eficiência energética em projetos de obras complexas, relatando um estudo de caso em projeto de aeroportos. $\mathrm{O}$ atendimento aos requisitos de eficiência energética tende a aumentar ainda mais a complexidade do processo de desenvolvimento do produto (PDP) na construção civil. Torna-se necessário, então, buscar instrumentos gerenciais que auxiliem o projetista a analisar as restrições e tradeoffs no PDP ao mesmo tempo em que se considere a agregação de mais valor ao produto, tanto sob o ponto de vista do cliente como do meio ambiente. A decisão de analisar o processo de projeto de aeroportos surgiu pelo fato de essas edificações serem caracterizadas pela complexidade e por apresentarem alto consumo energético e grande impacto ambiental. A partir de uma etapa de revisão bibliográfica, foram identificados os requisitos de eficiência energética a serem considerados na prática de projeto. $\mathrm{O}$ estudo teve sequência com a elaboração do macromapeamento do PDP, em um estudo de caso. Os resultados alcançados consistem na análise crítica do PDP e na identificação de oportunidades de inserção dos requisitos de eficiência energética no processo de projeto aeroportuário, considerando as falhas no fluxo de informação entre os agentes envolvidos. Por fim, são apresentadas diretrizes para a inserção dos requisitos de eficiência energética identificados a

Fernanda Selistre da Silva Scheidt Departamento de Construção Centro de Tecnologia e Urbanismo Universidade Estadual de Rodovia Celso Garcia Cid PR 445, km 379, Campus Universitário Caixa-Postal: 6001 Londrina - PR - Brasil CEP 86051-990

Tel.: (43) 3371-4460 E-mail: fselistre@terra.com.br

Ercília Hitomi Hirota Departamento de Construção

Centro de Tecnologia e Urbanismo

Universidade Estadual de Londrina

E-mail: ercilia@uel.br

Recebido em 18/02/2010 Aceito em 07/05/2010 partir da revisão bibliográfica no processo de projetos de aeroportos.

Palavras-chave: Processo de projeto. Gestão da informação. Eficiência energética.

\section{Abstract}

This paper discusses the management of information at the design stage for the consideration of energy efficiency requirements in complex construction projects. It reports a case study in design of airports. The consideration of energy efficiency requirements tends to increase the complexity of the Product Development Process $(P D P)$ in construction. It is necessary then, to develop tools for supporting the designer on the analysis of constraints and tradeoffs at the design stage, and at the same time to consider the addition of more value to the product, both from the point of view of the client and the environment. The decision to examine airports designs is due to the fact that they are characterized by complexity, have high energy consumption and high environmental impact. Based on a literature review, some constructs and variables have been identified, in order to guide data collection, and the mapping of the PDP in a case study. The results consist of the critical analysis of the PDP and the identification of opportunities for the integration of energy efficiency requirements in the design process of airports, considering the flaws observed in the flow of information among those involved. Finally, the paper proposes some guidelines for the integration of energy efficiency requirements identified from the literature review in the design of airports.

Keywords: Design process. Information management. Energy efficiency. 


\section{Introdução}

O sucesso econômico das empresas está ligado diretamente à capacidade de identificação das necessidades dos clientes e à criação de produtos capazes de satisfazê-las a um custo de produção relativamente baixo. Para tanto, o gerenciamento e o controle sobre as atividades de desenvolvimento do produto têm se tornado um ponto focal devido ao aumento da competitividade entre empresas e mercados mais exigentes e fragmentados.

Para Ulrich e Eppinger (2000), o PDP diz respeito ao conjunto de atividades interdisciplinares que se iniciam com a identificação de requisitos do cliente e terminam com a entrega do produto fabricado ao cliente, passando pela concepção, projeto e fabricação.

Em ambientes altamente competitivos, o processo tradicional de desenvolvimento do produto, de caráter sequencial, tem se mostrado ineficiente, devido ao reconhecimento tardio das necessidades dos clientes (HUOVILA; KOSKELA; LAUTANALA, 1997).

Koskela e Huovila (1997) ressaltam que o valor agregado ao produto pode ser incrementado com a redução dos custos devidos às atividades que não agregam valor ao produto final, como transporte, inspeção, esperas ou estoques. Essas atividades, consideradas perdas do processo, podem ser reduzidas, especialmente na etapa de projeto, mediante a adoção de estratégias como a análise rigorosa dos requisitos e necessidades junto aos clientes, a sistematização da coleta desses requisitos e maior interação entre os agentes envolvidos no processo.

A consideração dos requisitos de eficiência energética no PDP de produtos na construção civil é uma demanda nova para esse mercado, que aumenta ainda mais a complexidade do processo. Torna-se necessário, então, buscar instrumentos gerenciais que auxiliem o projetista a analisar as restrições e tradeoffs na etapa de desenvolvimento do produto, ao mesmo tempo em que se considera a agregação de mais valor ao produto, tanto sob o ponto de vista do cliente como do meio ambiente.

O setor da construção é caracterizado pela fragmentação e pela falta de integração entre os diversos agentes da cadeia produtiva. Isso representa uma das maiores barreiras à eficiência energética em edifícios (KORNEVALL, 2008).

O custo de uma construção ambientalmente correta não difere tanto do de um empreendimento usual (JOHN, 2008). Além disso, as vantagens da eficiência energética vão além da questão financeira: não deixam de ser um desafio que agregará valor à obra.
Mascaró (2006) aponta que as relações entre as decisões de projeto e o custo total do edifício são muito pouco conhecidas, mas elas existem e são muito claras. O desconhecimento da influência relativa de cada uma das variáveis no custo total da obra faz com que, diante de limitações orçamentárias, sejam efetuadas restrições e economias em todos os itens possíveis, ação que resulta, muitas vezes, em perdas de qualidade sensivelmente mais significativas do que a economia obtida.

No que se refere à análise da relação de custos com os requisitos de redução do consumo energético, alguns aspectos relevantes merecem ser citados, como o gasto de energia incorporado aos materiais devido ao volume de produção, distância e meio de transporte. Na Europa, aproximadamente 50\% da energia consumida é usada para a construção e manutenção de edifícios, e outros $25 \%$ são gastos em transporte (LAMBERTS; TRIANA, 2007).

$\mathrm{O}$ consumo de energia pode ser ainda maior na fase de uso das edificações. No Brasil, estima-se que as edificações são responsáveis por $48 \%$ do consumo de energia elétrica, considerando-se os setores residenciais e comerciais. As estatísticas mostram que o potencial de conservação em prédios já construídos pode ser de até $30 \%$, chegando a $50 \%$ em prédios novos (ELETROBRAS, 2003).

Os aeroportos estão entre aqueles que consomem mais energia, devido à complexidade da infraestrutura necessária para sua operação.

\section{Revisão de literatura}

\section{Processo de projeto}

A natureza do processo de projeto abrange processos intelectuais e processos gerenciais (TZORTZOPOULOS, 1999). Para Manzione (2006), a abordagem do projeto como um processo intelectual busca compreender como os projetistas pensam e desenvolvem soluções, sugerindo que a discussão do processo possa ser desenvolvida independentemente dos vários contextos técnicos no qual o projeto é praticado. Nesse processo, criatividade e intuição são fatores de grande relevância. A característica-chave do processo criativo é a ferramenta do desenho e, com relação a isso, Tzortzopoulos (1999) pondera que uma desvantagem em se projetar por meio de desenhos é que os problemas não são visualmente aparentes e tendem a não chamar a atenção dos projetistas.

A abordagem do projeto como processo gerencial identifica e relaciona a prática de projeto dentro do 
macroprocesso de gestão de empreendimentos. Assim, o projeto é relacionado a todas as etapas do ciclo de vida do produto, desde as fases iniciais até o acompanhamento do uso e manutenção, visando a melhorias na gestão do processo mediante a identificação das interfaces do projeto com todos os processos envolvidos na concepção do produto final (MANZIONE, 2006).

Para Winch (2002), clientes investem em utilidades que trazem benefícios e, consequentemente, o retorno do investimento realizado. Para esse autor, o mais importante na definição de projeto é entender como essa utilidade é gerada. Para isso, a chave é a análise do processo.Processo de projeto no PDP e suas abordagens

A literatura fornece diversas definições para o PDP (KOSKELA, 2000; ULRICH; EPPINGER, 2000; WINCH, 2002). Entre elas, a mais próxima à indústria da construção é a de Ulrich e Eppinger (2000). Estes autores definem o PDP como um processo pelo qual o produto é concebido, projetado e lançado no mercado, incluindo a fase de retroalimentação das etapas de produção. O processo tem início na percepção de mercado, ou seja, tipicamente envolve a identificação dos requisitos do cliente, a tradução destes em especificação de projeto, o desenvolvimento de um conceito, o projeto do produto, a validação do produto, o lançamento no mercado e, por fim, a coleta e a disseminação de informações para retroalimentação do processo.

Koskela (2000) identifica grandes semelhanças entre o processo de projeto e o de produção. O mesmo autor defende o entendimento do processo de projeto como uma combinação de processos de conversão, fluxo e geração de valor. Tal entendimento deu origem à teoria TFV (transformação, fluxo e geração de valor).

Koskela (2000) argumenta que, apesar de o sistema de produção e a prática de projeto apresentarem métodos e práticas diferentes, a teoria TFV fornece uma base teórica para o projeto.

O conceito de projeto como transformação trata o ato de projetar como a conversão de requisitos do cliente em especificações de produto que sejam capazes de atender a esses requisitos. Essa abordagem propõe que o trabalho a ser executado pode ser feito pela subdivisão do todo em partes, em que cada atividade é desempenhada por um especialista. Assim, a melhoria do processo de projeto seria ocasionada pela maior eficiência das partes.

A abordagem do projeto como fluxo deriva dos conceitos de gestão da qualidade e considera a informação como o principal input de projeto. Assim, está focada no caminho que a informação percorre até a conversão em projeto, considerando atividades de transporte, espera e inspeção dessas informações.

A abordagem do projeto como geração de valor enfatiza o valor gerado pelo projeto para os clientes. Pode ser entendido como a conversão de requisitos no projeto de um produto.

Ao equiparar o processo de projeto ao de produção, Huovila, Koskela e Lautanala (1997) consideram que no processo de projeto somente atividades de conversão podem ser consideradas como agregadoras de valor. Dessa forma, as demais atividades são consideradas como perdas, que devem ser eliminadas ou executadas de modo mais eficiente.

Koskela (2000) pondera que os conceitos de transformação, fluxo e geração de valor não são alternativos e não competem entre si; muito pelo contrário, se complementam no processo de gestão da produção.

É importante salientar que existem diferenças intrínsecas entre a produção física (ou material) e a atividade de projeto, uma vez que: a) há muito mais interações no projeto do que na produção física; b) existe muito mais incerteza no projeto do que na produção; c) em geral, o projeto é uma atividade não repetitiva, enquanto a produção envolve processos repetitivos; d) no projeto há dificuldade para determinar quando o trabalho está concluído, enquanto na produção o trabalho é feito ou não é feito; e e) no projeto os requisitos do cliente são traduzidos em uma solução (de projeto), enquanto na produção essa solução de projeto é realizada (KOSKELA, 2000).

\section{Mapeamento do fluxo de informações}

Atentar para o valor da informação tornou-se fatorchave para o êxito dos negócios e reporta as organizações para a complexa habilidade de gerenciar esse recurso, visando alcançar os objetivos estabelecidos com maior eficiência e eficácia dos processos.

Muitas vezes, os termos "dados" e "informações" são usados indistintamente, quando, na verdade, designam dois diferentes conceitos. Segundo Davenport (1998), dados são incapazes de diminuir o grau de nossas incertezas e não fornecem qualquer base sustentável para a tomada de decisão. Para Angeloni (2003), dados são elementos brutos, desvinculados da realidade e sem significado. No entanto, eles constituem a matéria-prima da informação. Dessa forma, dados sem qualidade levam a informações e decisões da mesma natureza. 
Sendo o dado considerado a matéria-prima para a informação, Nascimento (1999) define a informação como um recurso organizacional, resultante da ordenação de dados manipulados pelos diversos usuários envolvidos nos processos produtivos de uma empresa, com o objetivo de racionalizá-los e otimizá-los.

A origem, processamento, utilização e destino das informações no âmbito da construção civil vêm ocorrendo de forma inadequada dentro das organizações (NASCIMENTO, 1999). Devido à presença de inúmeros agentes, de formações diferentes, as informações geradas durante o PDP são muito diversificadas e geralmente estruturadas de maneira não integrada, fazendo com que haja negligência com relação à qualidade das informações geradas.

Aouad (1996) ressalta a importância da integração das informações no PDP e define integração como "a habilidade de partilhar informações entre os diferentes atores usando um modelo comum desenvolvido dentro de uma estrutura segura e confiável". Ou seja, o compartilhamento integrado das informações deve ter início na fase de captação das necessidades dos clientes e perdurar durante todo o processo de PDP, inclusive na fase de retroalimentação.

De acordo com Damelio (1996), o mapeamento e o uso de fluxogramas tornam o trabalho visível. Essa visibilidade proporciona a melhoria da comunicação e entendimento entre as partes, criando um modelo comum (AOUAD, 1996), a todos os envolvidos no processo de trabalho.

Dessa forma, a análise do processo por meio do mapeamento do fluxo de informações não só ajuda a orientá-lo para a satisfação dos clientes como também proporciona a identificação de ações que podem ser tomadas para a redução do tempo de ciclo, redução de erros, redução de custos, redução de fases que não agregam valor ao produto e, como consequência de tudo isso, aumento da produtividade.

\section{Requisitos}

Kamara, Anumba e Evbuomwan (2000) apontam que os requisitos do cliente correspondem às funções, atributos e demais características do produto ou serviço requerido por um cliente. Assim, os requisitos se referem às expectativas e necessidades do cliente final, bem como de outros clientes (internos e externos ao processo).

De acordo com Miron (2002), o foco sobre as necessidades dos clientes, também tratado por vários autores como geração de valor para o cliente (KOSKELA, 2000; WOODRUFF, 1997), tem demandado uma visão mais ampla sobre as atividades necessárias ao desenvolvimento de um produto.

A bibliografia permite definir valor como uma percepção do cliente com relação aos atributos e desempenho do produto ou sensação de satisfação que o cliente tem com relação ao uso do produto. A medida desse valor decorre da necessidade de realização de tradeoffs entre os benefícios obtidos e os sacrifícios requeridos pelo cliente (BUTZ; GOODSTEIN, 1996; SALIBA; FISHER, 2000; ULAGA; CHANCOUR, 2001; WOODRUFF, 1997).

De acordo com Koskela (2000), o desenvolvimento de soluções de projeto mais adequadas às necessidades dos clientes resulta das definições dos estágios iniciais de concepção, responsáveis por gerar valor às fases posteriores do processo. Nesse contexto, nos projetos de edificações, observa-se grande dificuldade na definição e na utilização de informações inerentes aos requisitos do cliente.

Koskela e Huovila (1997) ponderam que a necessidade de considerar inúmeros tipos de usuários dificulta a consolidação de um conjunto de requisitos bem definidos. Os mesmos autores ainda apontam que requisitos previamente identificados, muitas vezes, acabam não sendo contemplados na solução final devido às falhas na transmissão de informações, que provocam a perda desses requisitos durante o processo.

\section{Ferramentas de identificação e priorização de requisitos}

Considerando as dificuldades existentes no processo de manipulação de informações no processo de projeto, fica clara a necessidade da utilização de ferramentas de auxílio na elaboração e na priorização dos requisitos de projeto.

Para tanto, a bibliografia apresenta estudos que citam a utilização do Quality Function Deployment (QFD) (LIMA, 2007), da Técnica de Mudge (PANDOLFO, 2001), Análise de Custos por Funções, entre outras.

Apesar da existência de alguns trabalhos desenvolvidos na área, Jacques (2000) afirma que a complexidade do produto edificação e a interrelação de todas as suas funções acabam por limitar a utilização de tais ferramentas no PDP, no contexto da construção civil. No entanto, a autora pondera que, mesmo sendo utilizadas de forma parcial, essas técnicas mantêm sua importância no sentido de possibilitar que muitas variáveis do produto edificação sejam explicitadas, facilitando a 
compreensão, disseminação e priorização das necessidades dos clientes e seus requisitos.

A identificação e a análise dos requisitos dos clientes devem ser feitas o mais cedo possível, para que a tomada de decisão tenha o grau de incerteza reduzido pela qualidade da informação captada na análise.

\section{Eficiência Energética}

É incontestável que a energia é um recurso essencial para a vida humana, para a qualidade de vida dos cidadãos, e um dos maiores fatores vinculados ao desenvolvimento socioeconômico de qualquer nação.

Desde o início da década de 80, a questão energética tem sido amplamente discutida, pois, além de mover nossa civilização, é antes de tudo uma questão ambiental que compõe junto aos temas água e aquecimento global o rol das grandes causas e efeitos que serão debatidos e polemizados no século XXI. A energia não é tratada somente como um bem de consumo, mas está vinculada também à responsabilidade social do uso de um recurso natural escasso, cujas transformação e utilização afetam diretamente o meio ambiente.

O grande desafio dos programas que promovem maior eficiência energética é fomentar o discernimento de que as oportunidades do uso racional e eficiente de energia não se restringem apenas aos sistemas elétricos, mas abrangem diversos pontos e etapas do processo produtivo.

O macrocomplexo da construção civil e seus produtos, particularmente edifícios, consomem grande quantidade de energia, desde a construção até, e principalmente, a fase de uso.

No atual cenário de crescimento econômico, a utilização racional de energia tem potencial de fomentar ainda mais a competitividade entre empresas do ramo da construção civil.

\section{Estudos desenvolvidos no campo das edificações}

Até o presente momento os estudos no campo da eficiência energética em edificações se resumem à medição dessa eficiência em determinadas tipologias, ou simulação de projetos arquitetônicos em programas computacionais.

Em 1986 foi instituído o Programa Nacional de Conservação de Energia Elétrica (PROCEL), cujo objetivo é promover a racionalização da produção e do consumo de energia elétrica, para que os desperdícios sejam eliminados e os custos e os investimentos setoriais sejam reduzidos. Esse programa segue o conceito de que a conservação da energia elétrica se traduz na melhoria de sua utilização, sem abrir mão do conforto e das vantagens que ela proporciona. A importância dessa abordagem é que, em termos de implicações ambientais e considerando a tecnologia hoje disponível, economizar energia é mais barato do que produzi-la (BRASIL, 2002). Além disso, a economia obtida dessa forma se reverte em ganhos ambientais, devido ao menor impacto ambiental ou ao menor nível de poluição no que diz respeito à geração de energia. Isso ocorre sem que haja qualquer tipo de investimento, somente como um efeito da conscientização das pessoas. Pode-se dizer que a eficientização, a redução do consumo e o combate ao desperdício de energia são a fonte de produção mais barata e mais limpa que existe (ELETROBRAS, 2009).

O Comitê Gestor de Indicadores e Níveis de Eficiência Energética (CGIEE) é o responsável pelo estabelecimento dos índices e regulamentações para eficiência energética. Entre os estudos a serem elaborados pelo Comitê, destaca-se a definição de mecanismos de promoção de eficiência energética para edificações. Em termos de edificação, esses estudos objetivam verificar quais mecanismos podem ser utilizados para promover a eficiência energética nas edificações, ressaltando que:

A grande maioria das edificações
desperdiça relevantes oportunidades de
poupar energia e custos pela não
consideração efetiva, desde o projeto
arquitetônico, passando pela construção
até a utilização final, de importantes
desenvolvimentos nas áreas de novos
conceitos arquitetônicos, materiais,
equipamentos e tecnologias construtivas
vinculados à eficiência energética, dentro
do entendimento menor de que seus custos
são mais elevados, o que raramente é
verdadeiro [...]. Quando se concebe um
projeto integrado da edificação, ganhos
significativos em sustentabilidade podem
ser atingidos, tornando extremamente
favorável a relação benefício/custo. Da
mesma forma, técnicas de restauração de
edificações ("retrofits”)
aumentar substancialmente a eficiência
energética de prédios existentes. (BRASIL,
2002, p. 26).

Entre os trabalhos desenvolvidos no campo da eficiência energética em aeroportos, no Brasil, encontram-se aqueles realizados por pesquisadores do Programa de Pós-Graduação em Engenharia Civil da Universidade Federal de Santa Catarina (UFSC), sobre o potencial da geração fotovoltaica integrada a complexos aeroportuários, o que 
viabilizou a celebração de um Termo de Cooperação Técnica entre a Infraero e a UFSC, visando integrar aos aeroportos a utilização da energia solar como fonte de energia alternativa (BRAUN; JARDIM; RÜTHER, 2007).

O Grupo de Estudos e Desenvolvimento de Alternativas Energéticas (Gedae) da Universidade Federal do Pará também desenvolveu um trabalho nessa mesma linha utilizando o Aeroporto Internacional de Val-de-Cans (Belém, PA) como objeto de estudo (SANTOS; PINHO; MACÊDO, 2008).

\section{Eficiência energética com o enfoque de requisito}

Fabrício (2002) observa que a maioria dos empreendimentos de edifícios brasileiros é baseada em um leque restrito de tecnologias e sistemas construtivos. $\mathrm{O}$ fato de edificações serem tratadas como produtos únicos sugere flexibilidade para a introdução de inovações. No entanto, verifica-se que, no caso da construção civil brasileira, os canteiros de obra são bastante limitados com relação às soluções técnicas adotadas.

Dessa forma, inovações construtivas só são incorporadas quando proporcionam racionalização das construções, o que, consequentemente, desestimula grandes investimentos e mudanças radicais na base técnica do setor.

As inovações podem estar ligadas a materiais e componentes da construção bem como aos métodos construtivos. No que diz respeito a materiais e componentes construtivos, as inovações tecnológicas surgem predominantemente por iniciativa de grandes indústrias, limitando ainda mais a introdução destas na prática construtiva. Farah (1992) pondera que o processo de mudança é distorcido, pois as inovações não devem ser vistas como mera imposição dos fabricantes, como algo estranho à lógica do processo de construção. Pelo contrário, as necessidades da atividade de construção é que devem definir a viabilidade de determinada inovação.

Estudos mostram que o setor da construção civil, no Brasil, é o maior responsável pelo consumo nacional de energia, depois do setor industrial (LAMBERTS; TRIANA, 2007). Dessa forma, os projetos devem buscar redução nesse consumo e aumento do uso de fontes renováveis de energia, como alternativa às anteriores. Revela-se, então, a importância da consideração da eficiência energética como um dos critérios principais para o desenvolvimento dos projetos de edificações.

É plausível que a eficiência energética seja enquadrada como requisito na etapa de projeto, à medida que esta agrega valor ao produto, não somente sob o ponto de vista ambiental, mas também do cliente final. $\mathrm{O}$ uso racional de energia da edificação acaba sendo traduzido em economia monetária para o usuário.

\section{Normas e leis relacionadas à eficiência energética em edificações}

Devido ao fato de o presente trabalho tratar especificamente de edificações aeroportuárias, foi importante a análise do conteúdo das normas relacionadas à prática de projeto e construção de tais edifícios. Cabe lembrar que existem normas que orientam os profissionais de arquitetura nas áreas de desempenho térmico, iluminação e condicionamento de ar, mas elas não se referem à tipologia de aeroportos em particular.

Nessa vertente, existem também leis federais que favorecem a eficiência energética em vários campos, como a Lei no 9.991 (BRASIL, 2000), que dispõe sobre investimentos em eficiência energética por parte das empresas concessionárias, permissionárias e autorizadas do setor elétrico, e a Lei $\mathrm{n}^{\circ} 10.295$ (BRASIL, 2001), que dispõe sobre metas de eficiência energética em máquinas e aparelhos consumidores de energia e edificações.

No caso dos aeroportos, entre as referências de projeto está o Manual de Implementação de Aeroportos, elaborado pelo IAC. Em um de seus capítulos, o manual aborda a gestão e o controle do meio ambiente, com alguns itens relacionados à eficiência na fase operacional dos terminais. Nada consta com relação à etapa de projeto. $\mathrm{O}$ próprio IAC recomenda o uso desse manual apenas como referência, alegando que as orientações nele constantes não esgotam os assuntos abordados.

Manuais internacionais também são consultados para a concepção de um aeroporto. A IATA desenvolveu o Airport Development Reference Manual, que dispõe de ferramentas de auxílio ao zoneamento, pré-dimensionamento das áreas dos terminais de passageiros e de cargas, cálculo de tráfego, entre outras generalidades. Em seu capítulo 2, quando cita a elaboração de um plano diretor para aeroportos, apesar de sempre dar maior ênfase à emissão de gases como o principal impacto causado por essa tipologia, aponta que em termos energéticos os aeroportos causam muito menos impacto do que as pessoas pensam. Para justificar essa colocação, apresenta que a atividade de aviação corresponde a $5 \%$ do consumo anual mundial de petróleo e a cerca de $12 \%$ do abastecimento de petróleo utilizado pelo setor de transportes. Fica claro, então, que esses dados dizem respeito à fase de operação: esse manual não faz referência a nenhuma atitude que possa ser 
tomada na fase projetual, visando à eficiência energética (IATA, 1991).

Atualmente, surgem ferramentas de apoio aos projetistas para o desenvolvimento da eficiência energética já na fase de projeto das edificações. A ISO publicou recentemente a norma ISO 23045:2008, Building environment design Guidelines to assess energy efficiency of new buildings, que acentua a importância do processo integrado de concepção dos edifícios para a melhoria da eficiência energética. Ao fornecer diretrizes relativas à poupança de energia $\mathrm{e}$ valores-alvo de eficiência energética, fomenta a prática de projeto de maneira mais consciente com relação à energia.

A Standard Asharae 90.1, norma que é a base da análise energética da certificação LEED, na categoria Energia e Atmosfera, foi recentemente traduzida para o português. A Asharae também é a base da Lei Brasileira de Eficiência Energética 10.295/2001, que gerou o Regulamento Técnico da Qualidade do Nível de Eficiência Energética de Edifícios Comerciais de Serviços e Públicos (RTQ-C), pertencente ao Programa Brasileiro de Etiquetagem (PBE) do Inmetro.

\section{Identificação dos requisitos de eficiência energética em edificações}

No cenário internacional, o uso de diretrizes e normas tem sido efetivo no estabelecimento de medidas de eficiência energética em edificações (ELETROBRAS, 2003). No Brasil, em 2009 foi lançado o RTQ-C, a primeira norma brasileira de eficiência energética em edificações vigente no país. Mas o Ministério de Minas e Energia ainda sugere que normas internacionais que abordam a eficiência energética devam ser consultadas e criticadas, servindo de base para o estabelecimento de mecanismos de promoção da eficiência energética nas edificações brasileiras.

Já existem programas de certificação ambiental, amplamente utilizados em outros países, adaptados à utilização no contexto brasileiro. Pode-se citar o LEED, oriundo dos Estados Unidos, e o AQUA, ${ }^{1}$ adaptação do $\mathrm{HQE},{ }^{2}$ utilizado na França. Também está em vigor no Brasil o Programa Brasileiro de Etiquetagem. Essas ferramentas podem ser utilizadas de maneira complementar ao projeto, no que diz respeito à avaliação dos requisitos de eficiência energética. Com base nelas, é possível realizar a apuração dos principais itens relacionados à eficientização da edificação, que devem ser observados na fase de projeto.

Diante da análise dos diversos programas de certificação e etiquetagem de edificações em utilização no Brasil, é possível apurar os constructos e variáveis que podem ser considerados e estudados na fase de projeto de um aeroporto no que diz respeito à eficiência energética dessas edificações. A Figura 1 apresenta o mapeamento dos construtos e variáveis e as relações entre elas durante o processo de projeto.

A partir disso, conclui-se que os requisitos a serem observados na etapa de projeto de edificações que buscam a eficientização energética são:

(a) análise dos sistemas de energia da construção: potência instalada em todos os sistemas que consomem energia (iluminação,

condicionamento...);

(b) análise da envoltória da edificação: consideração do clima local para a escolha de materiais, estudo da orientação solar em função da economia nos sistemas de iluminação e condicionamento, presença de vegetação que cause sombra ou forme barreira para ventos, análise da topografia, proposição de melhorias que possam limitar desperdícios;

(c) desempenho da edificação com o consumo mínimo de energia: simulação em programas computacionais do comportamento da edificação em função da energia utilizada por seus sistemas e envoltória;

(d) gerenciamento dos refrigerantes: evitar o uso dos gases CFC e demais gases prejudiciais ao meio ambiente, buscar maior eficiência dos refrigerantes;

(e) uso de energia renovável: utilização de energia local, solar e eólica para alimentação dos sistemas instalados; e

(f) melhorias no comissionamento: assegurar que os sistemas da edificação sejam projetados, instalados, testados, operados e mantidos de acordo com as necessidades operacionais de cada um.

\footnotetext{
${ }^{1}$ AQUA (Alta Qualidade Ambiental): adaptação do processo de certificacão ambiental HQE para a realidade brasileira por meio da Fundação Vanzolini juntamente com professores do Departamento de Engenharia de Construção Civil da USP. ${ }^{2}$ HQE (Haute Qualité Environnementale): processo de certificação ambiental utilizado na França.
} 


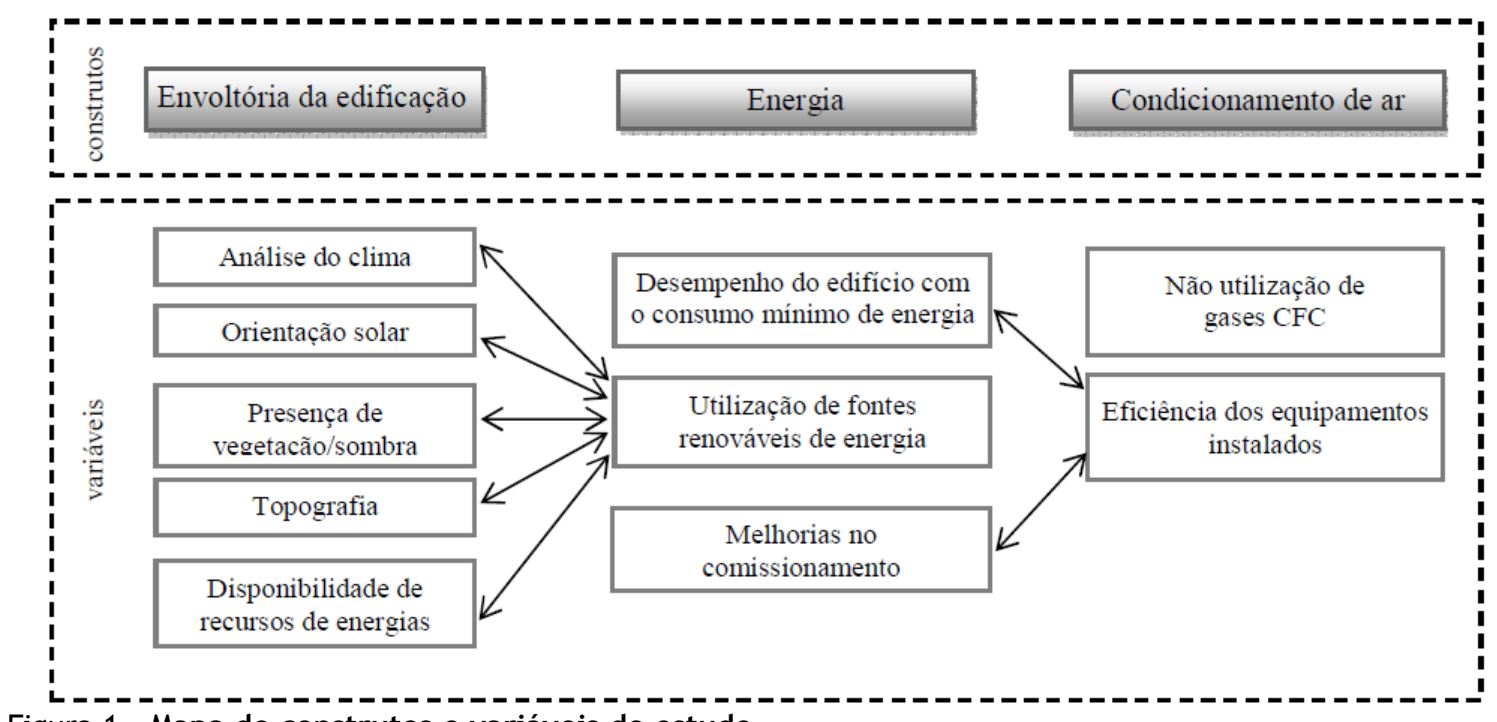

Figura 1 - Mapa de construtos e variáveis do estudo

Cabe lembrar que cada requisito tem seu método de análise e que alguns deles demandam o desenvolvimento ou uso de ferramentas já existentes para sua gestão na etapa de projeto.

\section{Método de pesquisa}

Buscando embasar as ações desenvolvidas ao longo do trabalho, a primeira etapa consistiu em revisão bibliográfica sobre o processo de projeto e eficiência energética.

Uma revisão bibliográfica sobre modelos de gestão de projetos, com enfoque no fluxo de informações, foi desenvolvida, em uma segunda etapa, para:

(a) entender quais são as variáveis abordadas no processo de projeto;

(b) entender a complexidade dessas variáveis e o fluxo de informações no processo de projeto; e

(c) identificar os problemas de projeto relacionados à consideração de requisitos de eficiência energética.

Uma terceira etapa envolveu a identificação dos requisitos de eficiência energética, também realizada por meio de revisão bibliográfica, resultando em um mapa de construtos e variáveis para a elaboração de um protocolo para o processo de coleta e análise de dados no estudo de caso desenvolvido. Paralelamente a essa série de revisões de literatura, foi desenvolvido um estudo de caso de caráter exploratório, com a finalidade de identificar em que momento os requisitos de eficiência energética podem ser incorporados no processo de projeto e como os agentes da cadeia podem utilizar as informações geradas após a incorporação desses conceitos.
O estudo exploratório teve início com a identificação de escritórios de arquitetura da cidade de Londrina que trabalham com projetos complexos. A decisão de analisar o processo de projeto de aeroportos surgiu por estes, além de serem caracterizados pela complexidade, apresentarem alto consumo energético e grande impacto ambiental.

Em seguida à identificação do escritório, fez-se uma análise de projetos para aeroportos novos e foi possível analisar de uma forma mais clara oportunidades para consideração de requisitos de eficiência energética. $\mathrm{O}$ projeto do aeroporto da cidade de Joinville (SC) foi eleito para o estudo devido à disponibilidade de informações detalhadas sobre ele.

A partir dos resultados das três etapas de revisão de literatura, e com base no protocolo de coleta e análise de dados, elaborou-se um mapa de fluxo de informações para análise do conteúdo, forma e momento de obtenção e repasse dessas informações.

$\mathrm{Na}$ intenção de contribuir para a evolução das práticas correntes no setor de projetos aeroportuários e de forma a cumprir seus objetivos, o trabalho em sua última etapa teve como objetivo propor um conjunto de diretrizes para a inclusão de requisitos de eficiência energética no modelo de gestão de projeto. Espera-se que as diretrizes propostas possibilitem que os estudos teóricos, resultantes da produção acadêmica, tenham alcance no cotidiano prático dos escritórios de projetos.

A validação das informações levantadas para a confecção do mapa de fluxo de informações foi realizada pelo engenheiro responsável pelas obras da regional sul da Infraero na época de construção do aeroporto de Joinville. Uma das reuniões 
também foi acompanhada pelo responsável pelo setor de manutenção na época, que hoje desenvolve um trabalho para melhoramento da gestão de energia em aeroportos.

\section{Estudo de caso de caráter exploratório}

A empresa de arquitetura analisada localiza-se na cidade de Londrina (PR) e tem como produto principal projetos de grande porte. Possui experiência em projetos aeroportuários, trabalhando nesse ramo desde 1995, tendo participado da concepção dos aeroportos de Londrina (PR) e de Joinville (SC), e reforma e ampliação do aeroporto de Foz do Iguaçu (PR), além de participar de vários concursos públicos desse tipo de obra.

À época do desenvolvimento do estudo, contava com uma estrutura constituída por um diretor (arquiteto), responsável pelo gerenciamento do processo de projeto, e um quadro de colaboradores composto de uma gerente de projetos (arquiteta) e três estagiários de arquitetura.

O objeto de estudo foi o aeroporto Lauro Carneiro de Loyola (Joinville, SC). Devido à proximidade de Joinville com Curitiba, o terminal é alternativa para pousos e decolagens quando as condições meteorológicas não permitem operações no Aeroporto Internacional Afonso Pena (Curitiba).

O aeroporto de Joinville opera somente voos domésticos nacionais e regionais. Foi inaugurado em 2004, com $4.000 \mathrm{~m}^{2}$ e capacidade para atender até 500 mil passageiros por ano. Localiza-se a aproximadamente $10 \mathrm{~km}$ do centro da cidade. A área do entorno é formada por matas de restinga e manguezais, o que condiciona possíveis propostas de expansão. O terreno do sítio aeroportuário está sujeito a inundações quando a maré alta associa-se a elevados índices pluviométricos, sendo esse um dos motivos das construções estarem a 1,0 metro acima do leito natural do solo.

\section{Coleta de dados}

A coleta de dados foi realizada buscando-se diferentes fontes de evidência para propiciar triangulação de informações. A coleta foi feita por meio de entrevistas semiestruturadas com o arquiteto-gerente da empresa responsável pelo projeto do aeroporto em estudo, e análise dos projetos e documentos (fax, atas de reunião, emails enviados e recebidos, anotações em projetos) disponíveis no acervo do projetista. As entrevistas foram realizadas com o auxílio de um gravador de áudio e bloco de anotações. É importante documentar a disponibilidade e apoio apresentados pelo arquiteto entrevistado, uma vez que o trabalho tornou-se um estímulo para possíveis melhorias na rotina de seu trabalho.

A primeira entrevista permitiu elencar os envolvidos no processo de projeto para posteriormente entender como funciona a estrutura dos principais órgãos envolvidos.

A Figura 2 ilustra o número de clientes internos e a relação criada entre eles ao longo do processo de concepção e obra do aeroporto de Joinville.

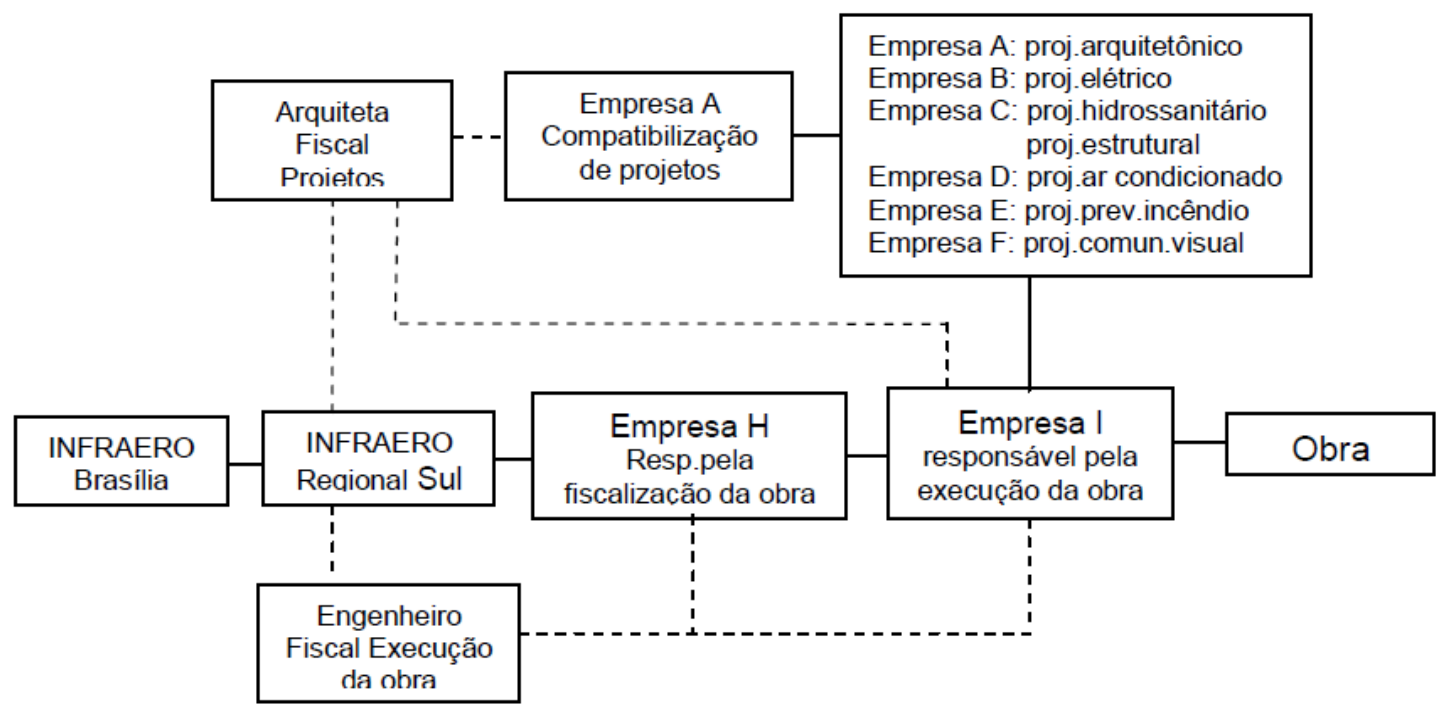

Figura 2 - Clientes envolvidos no processo e a relação entre eles 
As linhas tracejadas demonstram as relações diretas entre os representantes da Infraero e as empresas envolvidas no processo de projeto. Dessa forma, a empresa $\mathrm{A}$ foi a responsável pela compatibilização de todos os projetos, tendo a Infraero conhecimento dos problemas encontrados durante o processo por intermédio dela.

Uma arquiteta e um engenheiro da Infraero foram os responsáveis pela fiscalização das etapas de projeto e obra respectivamente. Esses dois profissionais tinham total autonomia para resolução de problemas e questões relacionadas à concepção do projeto, escolha de acabamentos e alterações do projeto durante a execução da edificação.

Uma vez que os profissionais disponibilizados para a fiscalização foram responsáveis por todas as obras de sua regional (RS, SC e PR), fez-se necessária a contratação, por meio de processo licitatório, de uma empresa para fiscalização direta da obra. Após a seleção da empresa que viria a executar a obra, esta passou a ser responsável pela contratação de todos os projetos complementares e pela compatibilização destes com o projeto arquitetônico.

Cada empresa subcontratada administrou seus trabalhos de forma isolada, até porque, muitas vezes, são escolhidas empresas de outras localidades que não do sítio do projeto. $\mathrm{Na}$ finalização do processo coube apenas à empresa contratada compatibilizar os projetos e identificar problemas que poderiam ter sido sanados no início do processo se o fluxo de informações entre os envolvidos tivesse oferecido subsídios para isso. Dessa forma, houve uma série de retrabalhos para muitos dos especialistas envolvidos, o que implicou maior demanda de tempo para a finalização do projeto.

\section{Macromapeamento do processo de projeto}

Por meio das entrevistas também foi possível traçar o macromapeamento, conforme a Figura 3, levantando todas as etapas que antecederam e influenciaram a concepção do projeto, assim como os intervenientes envolvidos em cada uma delas. Esse mapeamento é importante para o conhecimento de todos os limitadores e condicionantes para a etapa de elaboração do projeto.

O mapeamento foi formatado a partir de uma adaptação do modelo utilizado por Tzortzopolous (1999).

\section{Análise das etapas do processo mapeado e a inserção dos requisitos de eficiência energética}

A análise de cada etapa mapeada permitiu verificar que, além do termo "eficiência energética" não ser sequer citado, há o envolvimento de muitos agentes, com opiniões divergentes, os quais, em muitos casos, nem participam do processo do início ao fim, dificultando a consideração de requisitos de eficiência energética durante o projeto.

As informações coletadas por meio das entrevistas deixam claro que as atividades do órgão fiscalizador (Infraero) são exercidas de forma autoritária, condicionando a utilização de novas tecnologias para eficientização dos terminais à variável custo. Quando se fala da variável custo, é importante colocar que a Infraero administra 67 aeroportos, representando $97 \%$ do movimento aeroportuário brasileiro. Apenas 15 desses aeroportos podem ser considerados superavitários, ou seja, dão lucro para a estatal e assim cobrem os custos de funcionamento dos demais.

Os profissionais da Infraero, entrevistados na etapa de validação desse estudo, alegam que, mesmo de maneira indireta, a variável energia é considerada quando da construção de terminais. Um dos indicadores para a determinação do grau de desenvolvimento de uma nação é o perfil de consumo de energia: a matriz energética tem, então, impacto direto sobre o PIB e sobre toda a cadeia produtiva do país. O aeroporto, como um equipamento urbano e facilitador de negócios, insere-se nesse contexto produtivo. Ainda afirmam que, na matriz de custeio de aeroportos, a variável energia é muito forte e pode representar até $40 \%$ do custeio, dependendo do porte do terminal.

No projeto objeto de estudo, a Infraero optou pela utilização do projeto de Palmas (TO) como modelo e, de acordo com o projetista, o órgão buscava a utilização de um projeto de sucesso que pudesse ser replicado em várias regiões do país. Isso significa que, partindo da utilização de um projeto padrão, a envoltória da edificação, um dos requisitos considerados para o programa de etiquetagem voluntária de edificações, seria pouco considerado.

A inexistência de um sistema para comunicação entre os agentes também representa fator complicador. Eram realizadas reuniões mensais em Joinville, mas a maioria dos participantes do processo de projeto não residia ou trabalhava naquela cidade. As reuniões eram registradas em atas e tinham duração média de quatro horas. O número de participantes era de aproximadamente dezessete pessoas. Durante o período entre as reuniões mensais, a comunicação era feita por email ou fax, de forma isolada, ou seja, outros intervenientes que poderiam se interessar pelas informações que circulavam não tinham acesso a ela. Assim, a distância física entre os intervenientes do processo fez com que as dúvidas e os assuntos pendentes, que deveriam ser resolvidos em grupo, demorassem no mínimo um mês para ser discutidos. 


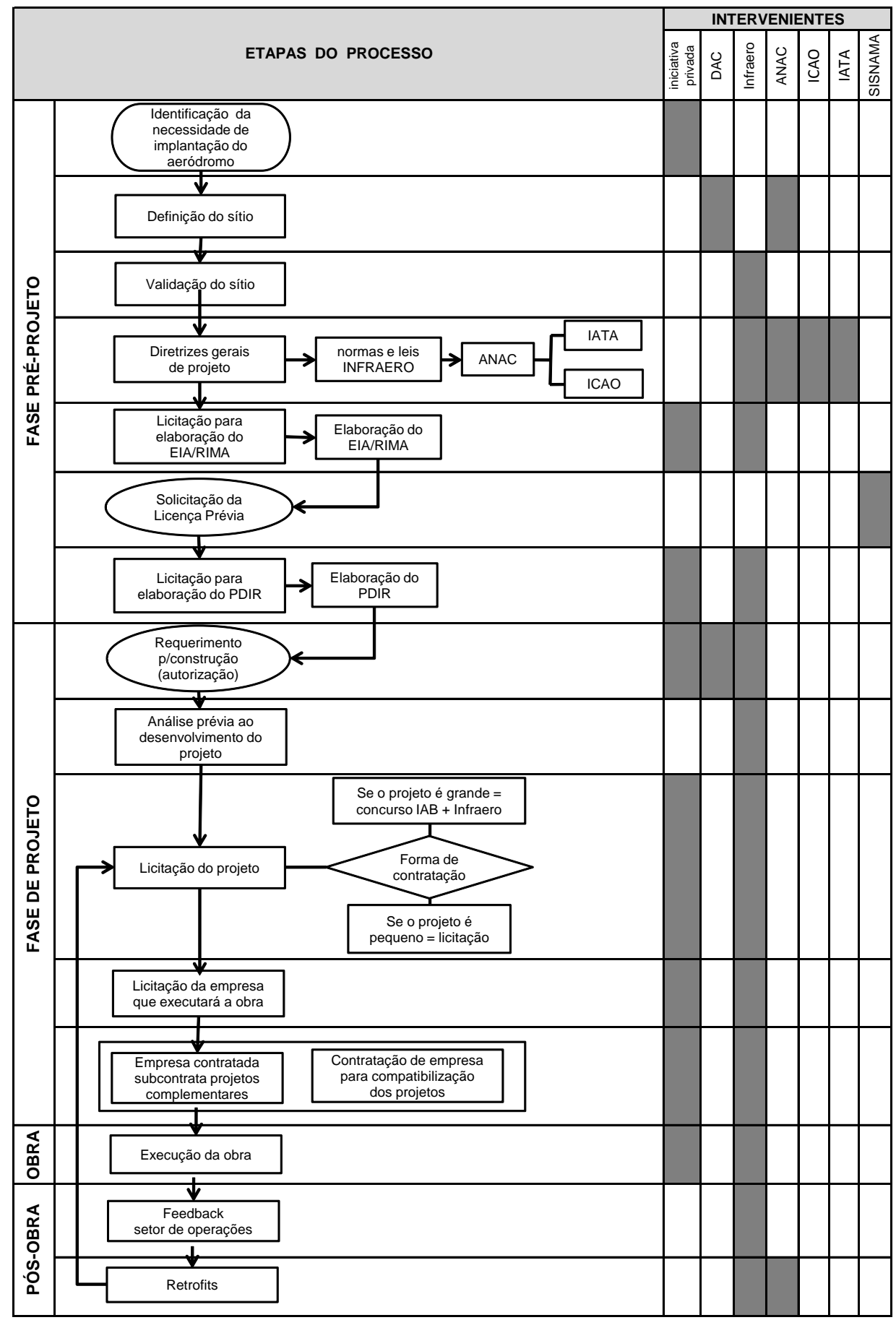

Legenda: $\square$ Momentos em que o interveniente participa de maneira efetiva na etapa do processo; iniciativa privada: esfera formada por empresários, companhias aéreas e parceiros; DAC: Departamento de Aviação Civil; Infraero: Empresa Brasileira de Infraestrutura Aeroportuária; Anac: Agência Nacional de Aviação; Icao: International Civil Aviation Organization; lata: International Air Transport Association; Sisnama: Sistema Nacional do Meio Ambiente.

Figura 3 - Macromapeamento do processo de projeto de um aeroporto

\section{Resultados alcançados}

Os resultados encontrados revelam que o projeto de aeroportos é uma atividade bastante complexa, condicionada a uma série de leis e normas, que envolve inúmeros intervenientes, de várias esferas e especialidades.
Por meio do estudo exploratório realizado, foi possível elencar todos os agentes envolvidos no processo de projeto de um aeroporto, assim como a hierarquia que se estabelece entre eles. O mapeamento do fluxo de informações possibilitou a identificação de lacunas importantes para a 
aplicação de requisitos de eficiência energética no PDP.

A partir da análise do mapa fica claro que, durante o processo de projeto, a preocupação com eficiência energética foi praticamente nula. $\mathrm{Na}$ época em que foi desenvolvido o projeto do aeroporto de Joinville, não estavam disponíveis para utilização os programas de certificação hoje amplamente divulgados e em crescente aplicação no mercado brasileiro de construção civil. Apesar disso, já existiam normas desenvolvidas no campo das edificações, como, por exemplo, a norma de desempenho térmico e a norma para condicionamento. $\mathrm{O}$ estudo do processo mostrou que não houve preocupação com a carga instalada em termos de iluminação, uma vez que o projeto elétrico foi realizado por um engenheiro eletricista, sem que houvesse um projeto luminotécnico específico para o aeroporto.

A falta de autonomia do arquiteto projetista nas decisões de projeto o torna dependente dos órgãos que regem e fiscalizam obras aeroportuárias. Isso implica maior demanda de tempo e geração de maior quantidade de informações a serem processadas pelos intervenientes.

A preocupação com a questão energética é recente no âmbito da Infraero. Tendo em vista os problemas enfrentados pelo país em 2001 quanto ao fornecimento de energia elétrica, a Infraero deu início a estudos sobre fontes alternativas para o suprimento de energia elétrica nos aeroportos. Entre essas alternativas, destaca-se a implantação de uma planta de cogeração de energia, na qual a energia elétrica necessária ao aeroporto é gerada no próprio sítio aeroportuário, por meio de grupos motor-gerador que utilizam como combustível o gás natural. Além da total independência em relação ao sistema convencional de fornecimento de energia elétrica, a cogeração apresenta menores custos de operação e manutenção, gerando como subproduto a água gelada necessária para o sistema de ar condicionado, o que leva a um custo final da energia elétrica compensador. Em 2002, iniciou-se a implantação desse sistema no aeroporto de Recife, tendo sido aprovada a viabilidade de implantação do projeto nos aeroportos de Maceió, Vitória, Santos Dumont, Galeão, Congonhas e Guarulhos (EMPRESA..., 2003).

Atualmente está em desenvolvimento um projeto piloto que será chamado de Plano Diretor de Energia, no qual a matriz energética do Aeroporto Salgado Filho (Porto Alegre, RS) será redesenhada em função de vários cenários. A ideia é que esse trabalho seja desenvolvido junto a alguma universidade, a qual irá estudar e desenhar os vários cenários. Esses cenários deverão considerar variáveis econômicas, sociais, políticas e ambientais, além de desenvolver para cada um deles estudos de viabilidade técnico-econômica. Com base no estudo dos diversos cenários, a Infraero desenvolverá o planejamento estratégico para o desenvolvimento dos projetos de engenharia e as obras.

A Figura 4 mostra as principais lacunas identificadas no processo no que diz respeito à consideração dos requisitos de eficiência energética já identificados.

\section{Diretrizes para inserção de requisitos de eficiência energética no processo de projeto de aeroportos}

O estudo exploratório permitiu a identificação de uma série de deficiências no processo de projeto que interferem diretamente na consideração dos requisitos de eficiência energética em edificações e que deram origem a diretrizes para a inserção desses requisitos no processo de projeto, apresentadas a seguir.

O fluxo do processo de projeto tem característica sequencial, no qual cada aspecto ou especialidade de projeto foi desenvolvido de maneira independente. Assim, a interação entre as diversas especialidades de projeto foi praticamente nula, fazendo com que as interferências fossem resolvidas com uma compatibilização ao final do processo. A sobreposição dos diversos projetos apontou a necessidade de adaptações das incompatibilidades. Nessa fase, qualquer alteração de projeto é onerosa, tendo em vista que a construção já está em andamento, com ciclos já encerrados e decisões que precisariam ser revistas em decorrência de demandas eventuais das etapas consecutivas.

Diante do exposto, o grande desafio consiste na transformação cultural dos agentes envolvidos no processo de construção de edificações aeroportuárias, inclusive dos órgãos públicos que gerenciam $o$ projeto e a construção de tais edifícios. $O$ poder público precisa perceber a importância do uso racional de seus recursos e da modernização de seus métodos de gestão das obras. 


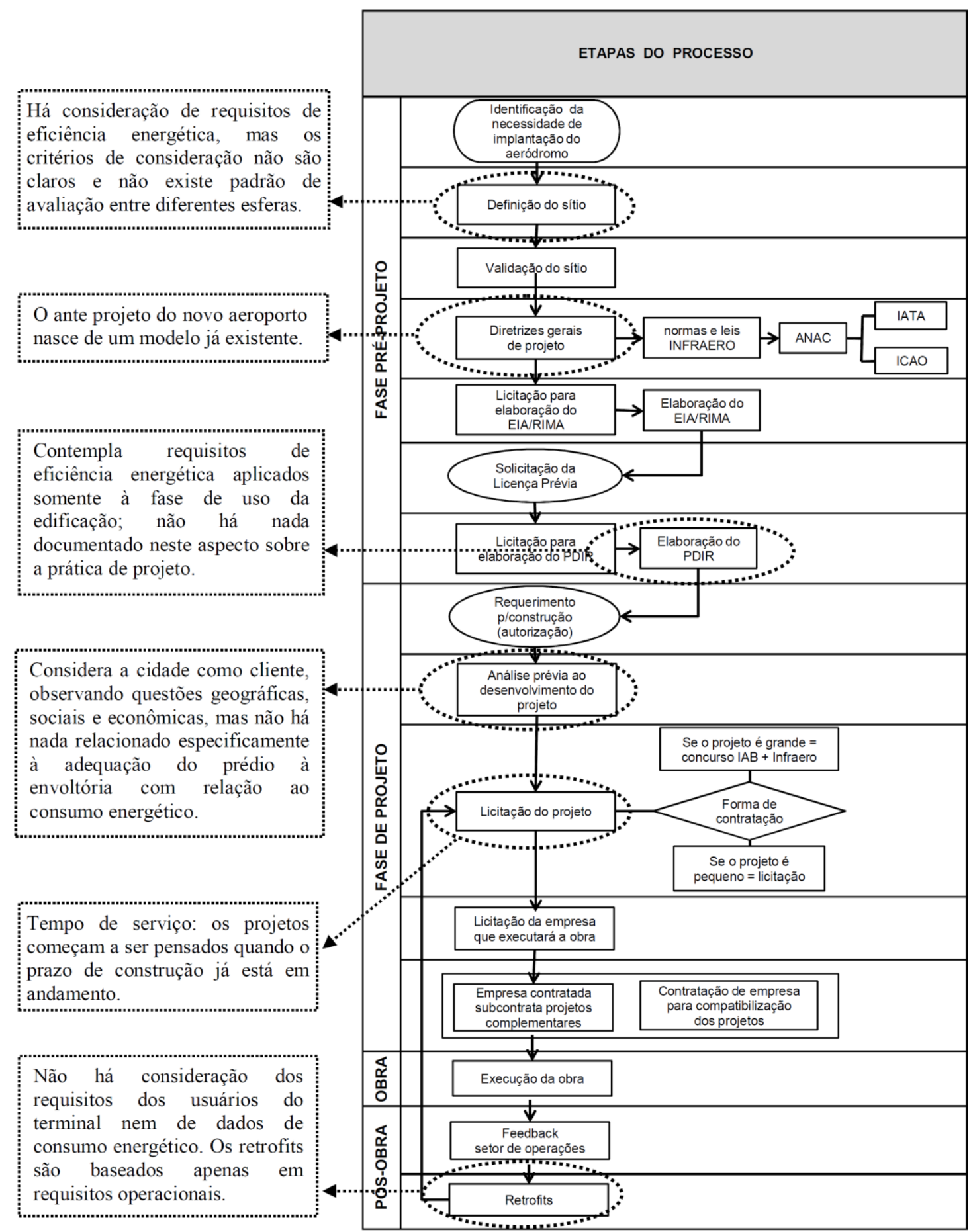

Figura 4 - Identificação das lacunas relacionadas à aplicação da eficiência energética em projetos de aeroportos

A consideração de requisitos de eficiência energética pode e deve ser realizada já nas fases iniciais de concepção dos projetos. Profissionais habilitados para a confecção de cada projeto devem ser contratados. Para que a eficiência energética seja aplicada de maneira a não prejudicar os usuários dos terminais, algumas especialidades antes não consultadas devem ser envolvidas no processo de projeto, como, por exemplo, um projetista especialista em iluminação, que confeccionará um projeto lumínico que considere o fator conforto.

Neste ponto é importante salientar que a demanda atual é maior no campo das reabilitações e retrofits dos terminais. Por meio das entrevistas constatouse que esses retrofits possuem como input apenas 
informações relacionadas ao setor operacional do aeroporto, sem considerar requisitos dos usuários nesse processo. Um dos pontos vulneráveis do departamento de engenharia da Infraero é que ele projeta e executa obras com base em alguns requisitos operacionais que são dinâmicos e não estão documentados.

A envoltória do edifício é item que afeta diretamente o desempenho energético de um aeroporto. Projetos padrão não são eficientes em qualquer sítio. Em muitos casos a eficiência energética seria beneficiada se fossem utilizados materiais locais que se adaptassem às características próprias de cada região do país. A simulação das edificações em programas computacionais específicos surge como uma alternativa de auxílio à tomada de decisão na fase de projeto. Fazer uso dessas ferramentas pode contribuir para a construção de edificações mais eficientes. Os planos diretores dão maior ênfase ao consumo de energia durante a fase de uso, mas deveriam considerar também os impactos das decisões de projeto sobre o desempenho energético da edificação.

A seleção de empresas com sede próxima ao local da obra é um facilitador para que haja maior interação entre os agentes envolvidos no processo de projeto. É evidente a importância dessa interatividade desde as fases iniciais de projeto, tornando o processo de compatibilização mais simples, visando à diminuição das alterações de projetos quando ciclos de produção já estiverem finalizados.

É importante relatar que avanços no campo de gestão de energia também foram observados junto à Infraero durante a realização da pesquisa. Hoje a empresa possui em sua estrutura uma área de meio ambiente e energia que cuida exclusivamente das questões ambientais e eficiência energética. Já se trabalha com energias alternativas, mas sempre considerando duas variáveis soberanas: a primeira delas é a segurança operacional dos terminais, que exige, por exemplo, níveis mínimos de iluminação de pista determinados pelo Icao; e a outra variável é o conforto do passageiro com relação, principalmente, ao condicionamento de ar. No entanto, a preocupação com a questão energética é muito recente e ainda está em processo de estruturação e desenvolvimento de soluções em fase piloto.

No que diz respeito à gestão da informação no processo de projeto, o aeroporto de Joinville foi o primeiro projeto a contar com um profissional responsável pela compatibilização. A empresa executora da obra foi quem subcontratou os projetos, escolhendo por sua conta as empresas com as quais trabalharia.

Com base nas recomendações do Tribunal de Contas da União (TCU), a Infraero hoje licita cada um dos projetos de um aeroporto, assim como a compatibilização final. Dessa forma, um profissional que pode não ter acompanhado absolutamente nada do processo de projeto pode vir a ser o responsável pela compatibilização dos projetos arquitetônico e complementares, ou seja, a gestão da informação nesse processo é extremamente dificultada pelo processo burocrático desenvolvido.

Apesar de a Infraero já demonstrar preocupação com variáveis ambientais e de energia, os critérios utilizados para avaliação delas em projetos não são claros e são balizados pelas questões operacionais. Não existe nenhum estudo ou intenção de mudanças na operação dos aeroportos em função do consumo energético ou impacto ambiental.

Diante do exposto, um grande passo seria a gestão do processo de projeto de aeroportos, a partir da consideração dos requisitos aqui identificados, nos programas de certificação, inclusive utilizando a metodologia proposta por eles para a inclusão e análise da eficiência energética nos projetos.

\section{Referências}

ANGELONI, M. T. Elementos Intervenientes na Tomada de Decisão. Ciência da Informação, Brasília, DF, v. 32, n. 1, p. 17-22, jan./abr. 2003.

AOUAD, G. Managing Construction Information Effectively Using Integrated Databases. In: CIB W65 INTERNATIONAL SYMPOSIUM FOR THE ORGANIZATION AND MANAGEMENT OF CONSTRUCTION, 1996, London.

Proccedings... London: CIB. v. 3, p. 14-22.

BRASIL. Lei no 10.295, de 17 de outubro de 2001. Dispõe sobre a Política Nacional de Conservação e Uso Racional de Energia. Brasília, DF, 2001

BRASIL. Ministério das Minas e Energia. Implementação da Lei de Eficiência Energética: relatório de atividades. Brasília, DF, 2002.

BRASIL. Lei no 9.991, de 24 de julho de 2000.

Dispõe sobre realização de investimentos em pesquisa e desenvolvimento e em eficiência energética por parte das empresas concessionárias, permissionárias e autorizadas do setor de energia elétrica, e dá outras providências. Brasília, DF, 2000. 
BRAUN, P.; JARDIM, C. S.; RÜTHER, R. Análise da Contribuição Energética de Sistemas Fotovoltaicos Integrados em Edificações: Aeroporto Internacional de Florianópolis: um estudo de caso. In: ENCONTRO NACIONAL, 9., ENCONTRO LATINO-AMERICANO, DE CONFORTO NO AMBIENTE CONSTRUÍDO, 5., 2007, Ouro Preto. Anais... Porto Alegre: ANTAC, 2007.

BUTZ, H. E.; GOODSTEIN, L. D. Measuring Customer Value: gaining the strategic advantage. Organizational Dynamics, New York, v. 24, p. 63-77, 1996.

DAMELIO, R. The Basics of Process Mapping. New York: Taylor \& Francis, 1996.

DAVENPORT, T. H. Ecologia da Informação: por que só a tecnologia não basta para o sucesso na era da informação. São Paulo: Futura, 1998.

ELETROBRAS. Relatório Anual. Rio de Janeiro, 2003.

ELETROBRAS. Apresentação do Programa PROCEL. Rio de Janeiro, 2009. Disponível em: $<$ http://www.eletrobras.gov.br/EM_Programas_Pr ocel/default.asp>. Acesso em: 12 out. 2009.

FABRICIO, M. M. Projeto Simultâneo na Construção de Edifícios. 2002. 350 f. Tese (Doutorado em Engenharia) - Escola Politécnica, Universidade de São Paulo, São Paulo, 2002.

FARAH, M. F. S. Tecnologia, Processo de Trabalho e Construção Habitacional. 1992. Tese (Doutorado) - Faculdade de Filosofia, Letras e Ciências Humanas, Universidade de São Paulo, São Paulo, 1992.

HUOVILLA, P.; KOSKELA, L.; LAUTANALA, M. Fast or Concurrent: the Art of Getting Construction Improved. In: ALARCÓN, L. (Ed.). Lean Construction. Rotterdam: A.A. Balkema, 1997. p. 143-159.

INTERNATIONAL AIR TRANSPORT ASSOCIATION (IATA). Airport Development Reference Manual. Geneva, 1991.

EMPRESA BRASILEIRA DE INFRAESTRUTURA AEROPORTUARIA (INFRAERO). Relatório Anual 2002. Brasília, DF, 2003.
JACQUES, J. J. Contribuições para a Gestão da Definição e Transmissão de Informações Técnicas no Processo de Projeto. 2000. 136 f. Dissertação (Mestrado em Engenharia Civil) Universidade Federal do Rio Grande do Sul, Porto Alegre, 2000.

JOHN, V. M. Premissas para Modelos de Certificação. In: ENCONTRO

INTERNACIONAL DE SUSTENTABILIDADE NA CONSTRUÇÃO, 2008. São Paulo. Anais... São Paulo: CTE, 2008.

KAMARA, J.; ANUMBA, C.; EVBUOMWAN, N. Establishing and Processing Client Requirements: a key aspect of concurrent engineering in construction. Journal of Engineering, Construction and Architectural Management, London, v. 7, n. 1, p. 15-28, 2000.

KORNEVALL, C. Relatório Síntese. São Paulo: CIB Megatrends, 2008.

KOSKELA, L. An Exploration towards a Production Theory and its Application to Construction. 2000. 296 f. Thesis (Doctoral in Technology) - Technical Research Center of Finland, VTT Building Technology, Helsinki, 2000.

KOSKELA, L., HUOVILA, P. On Foundations of Concurrent Engineering. In: ALARCÓN, L. (Ed.). Lean Construction. Rotterdam: A.A. Balkema, 1997. p. 22-32.

LAMBERTS, R.; TRIANA, M. Documento 2.2: levantamento do estado da arte: energia. São Paulo, 2007. Projeto Finep 2386/04.

LIMA, L. P. Proposta de uma Sistemática para o Processamento de Requisitos do Cliente em Empreendimentos Habitacionais de Interesse Social. 2007. 178 f. Dissertação (Mestrado) Escola de Engenharia, Universidade Federal do Rio Grande do Sul, Porto Alegre, 2007.

MASCARÓ, J. L. O Custo das Decisões Arquitetônicas. Porto Alegre: Masquatro, 2006.

MANZIONE, L. Estudo de Métodos de Planejamento do Processo de Projeto de Edifícios. 2006. 267 f. Dissertação (Mestrado em Engenharia de Construção Civil e Urbana) Escola Politécnica, Universidade de São Paulo, São Paulo, 2006. 
MIRON, L. I. G. Proposta de Diretrizes para o Gerenciamento dos Requisitos do Cliente em Empreendimentos da Construção. 2002. 150 f. Dissertação (Mestrado em Engenharia Civil) Escola de Engenharia, Universidade Federal do Rio Grande do Sul, Porto Alegre, 2002.

NASCIMENTO, V. de M. Método para Mapeamento do Fluxo de Informações do Processo de Suprimento na Indústria da Construção Civil: um estudo de caso múltiplo em empresas do subsetor edificações. 1999. Dissertação (Mestrado em Engenharia de Produção) - Universidade Federal de Santa Catarina, Florianópolis, 1999.

PANDOLFO, A. Modelo de Avaliação e Comparação de Projetos de Habitação com Base no Valor. 2001. 176 f. Tese (Doutorado em Engenharia de Produção) - Universidade Federal de Santa Catarina, Florianópolis, 2001.

SALIBA, M.; FISHER, C. Managing Customer Value: a framework allows organizations to achieve and sustain competitive advantage. Quality Progress, Milwaukee, v. 33, n. 6, p. 6369, Jun. 2000.

SANTOS, F. A. V.; PINHO, J. T.; MACÊDO, W. N. Estudo da Inserção de um Sistema Fotovoltaico Conectado à Rede no Complexo Aeroportuário de Belém-PA. In: CONGRESO IBÉRICO, 14., CONGRESO IBEROAMERICANO DE ENERGÍA SOLAR, 9., 2008, Vigo. Anais... Vigo: Asociación Española de Energía Solar, 2008.
TZORTZOPOULOS, P. Contribuições para o Desenvolvimento de um Modelo do Processo de Projeto de Edificações em Empresas Construtoras Incorporadoras de Pequeno Porte. 1999. 163 f. Dissertação (Mestrado em Engenharia Civil) - Escola de Engenharia, Universidade Federal do Rio Grande do Sul, Porto Alegre, 1999.

ULAGA, W.; CHACOUR, S. Measuring Customer-Perceived Value in Business Markets: a prerequisite for marketing strategy development and implementation. Industrial Marketing Management, New York, v. 30, p. 525-40, 2001.

ULRICH, K. T.; EPPINGER, S. D. Product Design and Development. London: McGraw-Hill, 2000.

\section{WINCH, G. M. Managing Construction}

Projects: an information processing approach. London: Blackwell Science, 2002.

WOODRUFF, R. B. Customer Value: the next source for competitive advantage. Journal of the Academy of Marketing Science, Greenvale, v. 25, n. 2, p. 139-153, 1997. 